\title{
Cost-price estimation of clinical laboratory services based on activity-based costing: A case study from a developing country
}

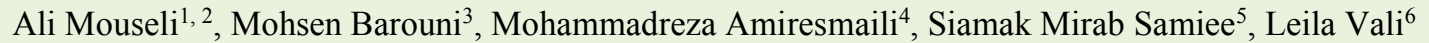

${ }^{1} \mathrm{PhD}$ Student in Health Care Management, Department of Health Management, Policy and Economic. Kerman University of Medical Sciences, Kerman, Iran

${ }^{2}$ Health Services Management Research Center, Institute for Futures Studies in Health, Kerman University of Medical Sciences, Kerman, Iran

${ }^{3}$ Assistant Professor, Modeling in Health Research Center, Institute for Futures Studies in Health, Kerman University of Medical Sciences, Kerman, Iran

${ }^{4}$ Associate Professor, Department of Health Management, Policy and Economic, Kerman University of Medical Sciences, Kerman, Iran

${ }^{5}$ Assistant Professor, Health Reference Laboratory Research Center, Ministry of Health and Medical Education, Iran

${ }^{6}$ Assistant Professor, Environmental Health Engineering Research center, Kerman University of Medical Sciences, Kerman, Iran

\section{Type of article: Original}

\begin{abstract}
Background: It is believed that laboratory tariffs in Iran don't reflect the real costs. This might expose private laboratories at financial hardship. Activity Based Costing is widely used as a cost measurement instrument to more closely approximate the true cost of operations.

Objective: This study aimed to determine the real price of different clinical tests of a selected private clinical laboratory.

Methods: This study was a cross sectional study carried out in 2015. The study setting was the private laboratories in the city of Kerman, Iran. Of 629 tests in the tariff book of the laboratory (relative value), 188 tests were conducted in the laboratory that used Activity Based Costing (ABC) methodology to estimate cost-price. Analyzing and cost-price estimating of laboratory services were performed by MY ABCM software Version 5.0.

Results: In 2015, the total costs were $\$ 641,645$. Direct and indirect costs were $78.3 \%$ and $21.7 \%$ respectively. Laboratory consumable costs by $37 \%$ and personnel costs by $36.3 \%$ had the largest share of the costing. Also, group of hormone tests cost the most $\$ 147,741$ (23.03\%), and other tests group cost the least $\$ 3,611(0.56 \%)$. Also after calculating the cost of laboratory services, a comparison was made between the calculated price and the private sector's tariffs in 2015.

Conclusion: This study showed that there was a difference between costs and tariffs in the private laboratory. One way to overcome this problem is to increase the number of laboratory tests with regard to capacity of the laboratories.
\end{abstract}

Keywords: Cost - Price, Clinical Laboratory, Laboratory Tests, Activity Based Costing, Private Sector

\section{Introduction}

Financial resources are the engine of the health system in the provision of services, and one of the main concerns of the public and private sectors executives and managers (1-3). But they are limited, and today in most countries, the health systems are faced with a financial crisis (1-3). Thus, the need for efficient use of financial resources is the necessity $(4,5)$, and managers must be able to provide health services at the lowest possible costs, while

\section{Corresponding author:}

Assistant Professor Dr. Leila Vali, School of Management \& Medical Informatics, Department of Health Management, Policy and Economic. Kerman University of Medical Sciences, Haft Bagh Highway, Kerman, Iran. Tel: +98.3431325165, Email: Vali1386@gmail.com

Received: September 13, 2016, Accepted: December 24, 2016, Published: April 2017

iThenticate screening: November 22, 2016, English editing: February 10, 2017, Quality control: March 04,2017

(C) 2017 The Authors. This is an open access article under the terms of the Creative Commons Attribution-NonCommercialNoDerivs License, which permits use and distribution in any medium, provided the original work is properly cited, the use is non-commercial and no modifications or adaptations are made. 
endeavoring to maintain quality $(6,7)$. Also, they should be aware of the cost of health services, and know how to allocate available resources $(6,7)$. But despite this important issue, in many developing countries, health system resources are badly managed, and a lot of them are wasted (8). One of the most widely used parts of the health system is the clinical laboratories department, as they provide diagnostic services through a variety of tests $(9,10)$. Laboratories play a key role in helping health care providers in clinical decisions for patients, and as a consequence, $60 \%$ to $70 \%$ of diagnoses are based on the results of laboratory tests $(11,12)$. In recent years, the demand for laboratory services has dramatically increased due to developments of new diagnostic tests and extensive advances in laboratory technologies (13). This issue along with direct and indirect costs of laboratory services has led to an increase of laboratory costs (3). Today, laboratory services account for around $10 \%$ of total costs of health system (11). Thus, laboratories, as an integral part of the hospital environment, should be looking for scientific ways to analyze and control costs $(1,2)$. Cost analysis plays an important role in policy making, and helps laboratory managers to develop appropriate strategies for real costing (14). This should be done accurately and based on scientific and economic methods $(10,11)$; otherwise, it could have undesirable effects on the continuity of services delivery due to high costs of equipment and consumable materials $(1,14)$. Cost control requires knowledge of resources and expenditure by the various sections of the laboratory, which can be achieved through access to systematic information in regard to expenses and activities and by using scientific methods of costing and its analysis. In this regard, Activity Based Costing ( $\mathrm{ABC})$, through considering the causal relationship between costs and activities, and providing managerial information in the form of financial criteria, is more useful than traditional accounting methods. $\mathrm{ABC}$ clearly reflects manpower, equipment, and activities of the section (15-17), provides real and accurate costs, and leads to increased efficiency, effectiveness and eventually achievement of the strategic objectives of the laboratory (18). Also with this method, direct and indirect costs for providing laboratory services can be determined. Furthermore, laboratory managers should identify the costly areas and estimate their costs against gained profit $(1,2,19,20)$. The city of Kerman, Iran with an area of 45,401 square kilometers and a population of around 750 thousand people, contains 61 laboratories. In 2015, 5,950,000 tests were conducted in the laboratories of the city which cost over $\$ 12,535,049$ (21). Since the number of laboratories increases every day and requested laboratory tests are also on the rise, it is expected that costs will also increase. Given the test price rise by inflation, some of these laboratories are not cost-effective due to the increased costs (21). This situation is at its worst in private laboratories. Kerman city has 34 private laboratories. The studied laboratory is one of the largest, with comprehensive coverage of most tests. In 2015, of the 84,515 persons referred, a total 591,607 tests were performed. In this year, the cost of performing these tests increased by more than 30 percent, while tariffs rose by only 7 to 8 percent (21). Therefore, the disproportion between increasing costs with determined tariffs will lead the laboratory to be unprofitable in the near future. Accordingly, the present study was conducted to estimate the costprice of laboratory services in private sector to provide basis for making real tariff.

\section{Material and Methods}

This cross-sectional study was conducted in 2015. The study setting was the 34 private laboratories in the city of Kerman, Iran. A private laboratory was selected in which, according to data of insurer institutions, most tests are performed, and due to easy access, a large number of patients referred. The most important fixed parameters used in this study included; laboratory area (153 square meters), three technical personnel, 4 support personnel, 2 service personnel and 1 pathologist in charge. Also, the monthly salary of the laboratory technician was $\$ 1,979$, technical personnel were \$330, and service personnel were \$990 and Logistical personnel were receiving \$264 per month. Of the 629 tests in the Laboratory's tariff book (relative value), 188 in 12 groups were performed in the studies laboratory, including: admission and sampling (4 tests), urine analysis (6 tests), clinical chemistry (38 tests), specialized clinical chemistry (21 tests), hormones (32 tests), tumor markers (6 tests), hematology (8 tests), coagulation (7 tests), blood banks (4 tests), serology and immunology (51 tests), microbiology (8 tests) and other tests ( 3 tests). In this study, all tests were used to calculate cost-price of the services. Calculating of the cost-price was performed using Activity Based Costing (ABC) methodology. All data and variables recorded in the relevant forms were first entered separately into Microsoft Excel, and after processing, the results were entered into MyABCM software version 5.0 to estimate the cost-price. Total cost was equal to: "Total Cost $=\Sigma$ Personnel cost + consumable goods cost + Depreciation cost + Building opportunity-cost + Energy cost + other cost".

Total cost was calculated based on $\mathrm{ABC}$ through the following steps (Figure 1): 


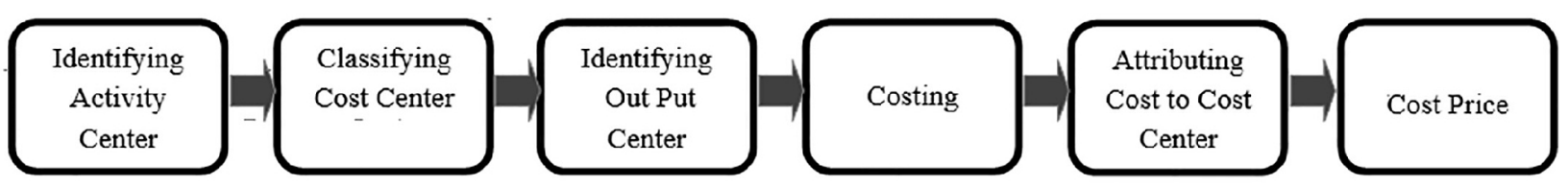

Figure 1. Activity Based Costing (ABC) Steps

Step 1: At this stage, activity centers were defined. An activity is a duty to achieve a set goal through man or machine, or a combination of both (2). Activity centers are places where all the tasks are done. The main factor in defining activities is their costs. Activity centers also have direct and indirect costs (14). Interview and observation methods were used to identify the centers of activity.

Step 2: At this stage, cost centers were classified, based on the type of operation they were undertaking. In this study, the direct cost centers were; human resources, consumable goods and depreciation costs, and indirect cost centers included; overhead costs, including administrative costs, energy, and so on.

Step 3: At this stage, output of each center was identified. In other words, this stage meant to identify output of each center. For instance: the output of hematology laboratory might be different. Since each center has different output with its own price, to do costing, cost centers were classified based on their own output, then costing process was initiated based on outputs (14).

Step 4: At this stage, costing was performed for each cost center. After studying and analyzing available evidence and documents, the costs related to each cost center (including; human resources, materials, equipment, depreciation, food and overhead costs) were determined. Costing basis for each cost center was the number of tests for human resources, consumable goods and depreciation cost and their space $\left(\mathrm{m}^{3}\right)$ for energy costs.

Step 5: At this stage, the calculated costs for each activity center was dedicated to the final cost centers.

Step 6: At this stage, the cost price was determined for each output. After identifying the costs related to the final cost centers or centers with output, cost price for each output was calculated by dividing the total allocated costs to each cost center, by a defined output for the center. The result of this calculation was the cost price of each output (22).

Step 7: Finally, at this stage, the costs of each cost center and share of each of the cost centers were compared and determined.

In this study, depreciation cost was calculated by the straight-line method; by dividing the cost of fixed assets' depreciation by assets' expected useful life. The useful life of equipment was calculated as approximately 10 to 15 years. Sharing basis for the cost center included; human resources, consumable goods and depreciation costs for the number of carried out tests and the amount of energy used for space (cubic meters). According to the Central Bank of the Islamic Republic of Iran at the time of the study, each US Dollar was equal to 30,315 Iranian rials. After calculating the cost of laboratory services, a comparison was made between the calculated price and the private sector's tariffs in 2015.

\section{Results}

In this study, the costs of different tests of the laboratory were calculated using ABC. As is shown in Table (1), in the studied laboratory, direct and indirect cost centers were $\$ 502,336(78.3 \%)$ and $\$ 139,309(21.7 \%)$ respectively. Also, the depreciation cost of specialized equipment required for all laboratory tests was $\$ 32,327$, the depreciation costs of other equipment was $\$ 20,954$, the cost of consumable goods was $\$ 237,382$, cost of professional human resources was $\$ 160,098$, cost of logistics was $\$ 72,529$, energy cost was $\$ 3,394$, the cost of rent was $\$ 69,024$, the cost of quality control was $\$ 39,987$ and other costs were $\$ 5,950$. Other costs were included; residual, council tax, repair and maintenance, hardware and software setup. In the studied laboratory, consumable goods cost the most $\$ 237,382(37 \%)$ and energy cost the least $\$ 3,394,(0.5 \%)$, (Table 1$)$. The cost of consumable goods and labor in the laboratory had the biggest share with; $37 \%$ and $36.3 \%$ respectively, (professional manpower $25 \%$ and logistical $11.30 \%$ ). In another part of this study, the calculation of the cost price and the cost of each of the test groups performed in the laboratory are being done. In this study, urine analysis cost $\$ 27,134$ which accounted for $4.23 \%$ of the total costs. Admission and sampling group cost $(\$ 20,966)$ which accounted for $(3.27 \%)$, specialized clinical chemistry cost $\$ 75,594,(11.78 \%)$, hormones group cost $\$ 147,741$, ( $23.03 \%$ ), tumor marker group cost $\$ 15,398$, (2.40\%), coagulation group cost $\$ 17,866,(2.78 \%)$, blood bank group cost $\$ 8,968,(1.40 \%)$, hematology group cost $\$ 50,925$, ( $7.94 \%$ ), serology and immunology group cost $\$ 104,909$, (16.35\%), microbiology group cost $\$ 34,831$, $(5.43 \%)$, and clinical chemistry group cost $\$ 133,702,(20.84 \%)$ of the total costs. In the studied laboratory, group of Hormones test cost the most at $\$ 147,741(23.03 \%)$ and the group of other tests cost the least at $\$ 3,611,(0.56 \%)$, (Table 2). 
http://www.ephysician.ir

Table 1. Direct and Indirect Cost Centers in studied Laboratory (2015).

\begin{tabular}{|l|l|l|l|}
\hline Cost Centers & Cost Amount (USD) & Cost sharing from total costs (\%) \\
\hline \multirow{4}{*}{$\begin{array}{l}\text { Direct Cost } \\
\text { Centers }\end{array}$} & Consumable Goods & 237,382 & 37.0 \\
\cline { 2 - 4 } & Depreciation of Specialized Equipment & 32,327 & 5.0 \\
\cline { 2 - 4 } & Professional Human Resources & 160,098 & 25.0 \\
\cline { 2 - 4 } & Logistical Human Resources & 72,529 & 11.3 \\
\hline \multirow{3}{*}{$\begin{array}{l}\text { Cendirect Cost } \\
\text { Centers }\end{array}$} & Energy & 3,394 & 0.5 \\
\cline { 2 - 4 } & Quality Control & 39,987 & 6.2 \\
\cline { 2 - 4 } & Rent & 69,024 & 10.8 \\
\cline { 2 - 4 } & Depreciation of Other Equipment & 20,954 & 3.3 \\
\cline { 2 - 4 } & Other & 5,950 & 0.9 \\
\hline
\end{tabular}

Table 2. Total Cost of studied laboratory based on separate laboratory tests (2015)

\begin{tabular}{|l|l|l|}
\hline Group of laboratory tests & Cost Amount (USD) & Cost sharing from total costs (\%) \\
\hline Admission and Sampling & 20,966 & 3.27 \\
\hline Urine Analysis & 27,134 & 4.23 \\
\hline Clinical Chemistry & 133,702 & 20.84 \\
\hline Specialized Clinical Chemistry & 75,594 & 11.78 \\
\hline Hormones & 147,741 & 23.03 \\
\hline Tumor Markers & 15,398 & 2.40 \\
\hline Hematology & 50,925 & 7.94 \\
\hline Coagulation & 17,866 & 2.78 \\
\hline Blood Bank & 8,968 & 1.40 \\
\hline Serology and Immunology & 104,909 & 16.35 \\
\hline Microbiology & 34,831 & 5.43 \\
\hline Other & 3,611 & 0.56 \\
\hline SUM & 641,645 & 100 \\
\hline
\end{tabular}

\section{Discussion}

According to the results of this study, the cost of consumable goods and labor in the laboratory had the greatest share with; $37 \%$ and $36.25 \%$ respectively, (professional manpower $24.95 \%$ and logistical $11.30 \%$ ). According to a Negrini et al. study in a hospital in Europe (23), Mehrol Hasani et al. in a laboratory of Shafa hospital in Kerman (3), Antonella et al. in the laboratory of Lacor hospital in Uganda (24), Nasirpour et al. in the laboratory of Vali-easr hospital in Tehran (14), Zamandi et al. in Tehran Imam Reza Hospital's hematology unit (25) and Hadian et al. in Fatimia hospital in Semnan (26), the cost of consumable goods were; 22\%, 21.1\%, 21\%, 15\%, 8.4\% and 2\% respectively, labor costs were; $49 \%, 74.2 \%, 17 \%, 44 \%, 33.5 \%$ and $48 \%$ of the total costs respectively. Also, according to a Torabi et al., study which was conducted in the Golestan Hospital's radiology in Ahvaz, human resources accounted for the most costs (43.3\% of all costs) (27). The high cost of consumable goods in the studied laboratory, compared to above mentioned studies, could be due to the high number of client visits that led to an increase in variables costs such as consumable goods. While, in the above mentioned studies, the costs of human resources as a fixed cost, has been accounted for the most costs. According to study results, the energy cost of $\$ 3,394$ accounted for $0.53 \%$ of the total cost of the laboratory. In the studies of Nasirpour et al. (14), Mehrol Hasani et al. (3), Negrini et al. (23), Zamandi et al. (25), Sabermahani et al. (28) and Mohammadi et al. (29) the energy costs accounted for $5 \%, 0.19 \%, 3.5 \%, 0.006 \%, 0.32 \%$ and $15 \%$ of the total costs respectively. As energy cost is a fixed cost, and government provides subsidies for the energy, and also as Iran is very rich in energy, the cost in the present study is similar to above mentioned studies. Based on the results, depreciation cost of the specialized and regular equipment accounted for $\$ 69,797$, which was $10.73 \%$ of the total cost of laboratory. In the studies of Hadian et al. (26), Nasirpour et al. (14), Mehrol Hasani et al. (3), Negrini et al. (23), Zamandi et al. (25), Antonella et al. (24) and Mobasheri et al. (30) the costs of depreciation were reported as; $6.7 \%, 17 \%, 2.80 \%, 7.4 \%, 6.5 \%, 17 \%$ and $13.7 \%$ of the total cost of equipments respectively. The high depreciation costs of the laboratory equipment could be due to their functional nature. Since the equipment is an expensive asset and has a relatively high depreciation, the costs of equipment depreciation have been reported high in this study and above mentioned studies. The results of present study showed that, the cost of rent was $\$ 69,024$ which accounted for $10.76 \%$ of the total cost of laboratory. In a Hadian et al. study, the cost of building accounted for $42 \%$ of the total costs (26). The high cost of rent in the studied laboratory was due to the location of the laboratory, as it is situated in an expensive part of the city in which 
the price of land is very high. Quality control cost in the present study was $\$ 39,987$ which accounted for $6.23 \%$ of the total cost of laboratory. The high cost of quality control is due to the important role it plays in laboratory services, thus, in order to be certain, regarding different aspects of quality in the performed tests, quality of services should be considered, as despite the high costs, in the long term, could significantly increase revenues in the laboratory. Other costs in the study were $\$ 5,950$ which accounted for $0.93 \%$ of the total cost of laboratory. Antonella et al. in their study showed that $45 \%$ of the total expenses of Lacor hospital were related to the general expenses (24). Since in the present study, other costs included expenses such as; residual, council tax, maintenance and repairs, and hard and software costs, it should be considered that, laboratory is costly and these expenses are inevitable to ensure quality of services provided in the laboratory. In another part of this study, the calculation of the cost price and the cost of each of the test groups performed in the laboratory, are being discussed. In this study, urine analysis cost $\$ 27,134$ which accounted for $4.23 \%$ of the total costs. In the Nasirpour et al. study, $29.9 \%$ of the total cost was related to urine analysis (14). The low cost of urine analysis tests could be due to lower demand for this test by clients. In this study, admission and sampling group cost $(\$ 20,966)$ which accounted for $(3.27 \%)$, specialized clinical chemistry cost $\$ 75,594$ (11.78\%), hormones group cost $\$ 147,741$ (23.03\%), tumor marker group cost $\$ 15,398$ (2.40\%), coagulation group cost $\$ 17,866$ (2.78\%), blood bank group cost $\$ 8,968$ (1.40\%), hematology group cost $\$ 50,925(7.94 \%)$, serology and immunology group cost $\$ 104,909,(16.35 \%)$, microbiology group cost $\$ 34,831,(5.43 \%)$, and clinical chemistry group cost $\$ 133,702,(20.84 \%)$ of the total costs. In the Nasirpour et al. study, hematology group cost $\$ 31,854$ which accounted for $(1.80 \%)$ of total costs, serology and immunology group cost $\$ 242,307$ (13.67\%), microbiology group cost $\$ 58,914$ (3.32\%), and clinical chemistry group cost $\$ 923,202$ $(52.08 \%)$ of the total costs (14). The amount of costs of each test group in studied laboratory were proportional to the number of client's visits and performed tests, therefore, the amount of cost has a rational figure and shows the amount of client's demand for each test group.

\section{Conclusions}

In this study, using Activity Based Costing method, it was found that there was a difference between cost-price and tariffs in private sector. In other words, tariffs have not been determined based on scientific and economic methods and they are less than the real costs of laboratory services in private sector. This has led to studied laboratory facing a budgetary deficit. Findings of current study can be used for cost-price estimating of laboratory services based on defined scientific steps, and consideration of all costs (direct and indirect) and developed tariffs actually and reasonably. It is suggested to overcome the budgetary deficit and financial problems of laboratories due to low tariffs, is to utilize maximum capacity of laboratories by increasing the number of laboratory tests as much as possible. Also, it can be done by decreasing cost-price of laboratory services through the use of appropriate human resource management techniques, multitask delegation to specialized personnel, using fully automatic equipment and devices, and implementing efficient inventory control techniques. Finally, it should be noted that this study may not be representative of the entire range of tests in any other laboratories in the country. Therefore, conducting complementary research on cost-price estimation in governmental and nongovernmental laboratories by using other methods, could be appropriate path for future research on this topic.

\section{Acknowledgments:}

This study is a part of a Ph.D. thesis in health care management at Kerman University of Medical Sciences. We thank Dr Mohammad Jafari Sirizi director of Iran health insurance organization, Kerman Office, for his kind assistance in different stages of the study.

\section{Conflict of Interest:}

There is no conflict of interest to be declared.

\section{Authors' contributions:}

AM conceived the study, participated in data collection and data analysis, as well as preparation of the manuscript. MB contributed to the development of data collection, carried out data analysis, and contributed to the writing and several edits of the manuscript. MA contributed to the writing and several edits of the manuscript, and contributed to the writing of the manuscript. SS participated in the design of study and contributed to the writing and editing of the manuscript. LV participated in study design, contributed to data analysis and writing of the manuscript, and is guarantor. All authors read and approved the final version of paper. 


\section{References:}

1) Jafari Sirizi M, Barouni M, Saber Mahani A. Analysis of Cost Price and Net Profit of Paraclinic Services in Private and Public Sectors: A Case Study of Kerman City 2014. Journal of Health Management and Informatics. 2015; 2(4): 138-43.

2) Yusefzadeh $\mathrm{H}$, Ghaderi $\mathrm{H}$, Bagherzade $\mathrm{R}$, Barouni $\mathrm{M}$. The efficiency and budgeting of public hospitals: case study of iran. Iran Red Crescent Med J. 2013; 15(5): 393-9. doi: 10.5812/ircmj.4742. PMID: 24349726, PMCID: PMC3838648.

3) Mehrolhassani MH, Heidari MR, Rahimi Z, Emami M. Cost Price Estimation of Clinical Laboratory Services in Shafa Hospital based on Activity-based Costing, Kerman, 2011. Quarterly Journal of Sabzevar University of Medical Sciences. 2014; 21(4): 587-95.

4) Abolhallaje M, Jafari M, Seyedin H, Salehi M. Financial Management Reforms in the Health Sector: A Comparative Study Between Cash-based and Accrual-based Accounting Systems. Iran Red Crescent Med J. 2014; 16(10): e15472. doi: 10.5812/ircmj.15472. PMID: 25763194 , PMCID: PMC4329747.

5) Saber-Mahani A, Goodarzi Gh, Barouni M, Khakian M. Estimation of Technical Efficiency of General Hospitals of Kerman University of Medical Sciences by Data Envelopment Analysis (DEA) Method in 2007. Journal of Kerman University of Medical Sciences. 2010; 17(1): 59-67.

6) Financing health services in developing countries: an agenda for reform. Washington DC, World Bank, 1987.

7) Nouroozi T, Salehi A. Prime costs of clinical laboratory services in Tehran Valiasr Hospital in 2009. East Mediterr Health J. 2014; 19 Suppl 3: S159-65. PMID: 24995740.

8) Newbrander W, Barnum H, Kutzin J. Hospital economics and financing in developing countries. Geneva, World Health Organization. 1992: 1-4.

9) Powell W, Snellman K. The knowledge economy. Annu Rev Sociol. 2004; 30: 199-220. doi: 10.1146/annurev.soc.29.010202.100037.

10) Bossuyt X, Verweire K, Blanckaert N. Laboratory Medicine: Challenges and Opportunities. Clin Chem. Clin Chem. 2007; 53(10): 1730-3. doi: 10.1373/clinchem.2007.093989. PMID: 17885139.

11) Solnica B, Dabrowska M, Sypniewska G. Laboratory Medicine as a Profession and Clinical Science-How to Perform both of them well? EJIFCC. 2010; 21(3): 53-5. PMID: 27683373 , PMCID: PMC4975248.

12) Henricks WH. Information System Issues Facing Clinical Laboratories Serving Complex Integrated Delivery Systems. Journal of Health Care Information Management. 2000; 14(3): 55-67. PMID: 11186799.

13) Wolper LF. Health care administration: plannjng, implementing and managing organized delivery system. 4th edition, USA: Jones and Bertlett, 2004.

14) Nasiripoor A, Tabibi J, Maleki M, Nourozi T. Computation Cost Price of clinical laboratories services in valiasr hospitals in Tehran in 1387 by using of ABC model. Journal of Hospital. 2010; 8(3 and 4): 5-17.

15) Stefano NM, Filho NC. Activity-based costing in services: literature bibliometric review. SpringerPlus. 2013: 2(80): 1-11. doi: 10.1186/2193-1801-2-80.

16) Gupta MC, Galloway K. Activity-based costing management and its implications for operations management. Technovation. 2003: 23(2): 131-8. doi: 10.1016/S0166-4972(01)00093-1.

17) Tsai WH. Activity-based costing model for joint products. Computer and Industrial Engineering. 1996; 31(3-4): 725-9. doi: 10.1016/S0360-8352(96)00246-X.

18) Salehi M, Hejazi R, Bashiri Manesh N. Activity based costing model for cost calculation in gas companies: empirical evidence of Iran. International Review of Accounting, Banking, and Finance. 2010; 2(1): 31-43.

19) Talaee Zavareh H. A Study on the Establishment of Performance-Based Budgeting Using the ABC Activity-Based Costing Technique in the Organization of Educational Research and Planning (OERP) of the Ministry of Education. Journal of Review Quarterly Journal of Educational Innovations. 2011; 9(36): $150-72$.

20) Mousavi SA, Khorvash F, Fathi H, Fadai H, Hadianzarkesh moghadam Sh. Survey the Average of Cost in out Patient and Imaging in Alzahra Hospital and Comparing with Service's Tariff. Journal of Health Information Management. 2010; 7(2(14)): 235-42.

21) Clinical Affairs Document of Kerman Province. 1th Ed. Research Center for Health Services Management, Institute of Futures Studies in Health, Kerman University of Medical Sciences Publication: Kerman, Iran; 2015.

22) Goeree R, Gafni A, Hannah M, Myhr T, Blackhouse G. Hospital selection for unit cost estimates in multicentre economic evaluations. Does the choice of hospitals make a difference? Pharmacoeconomics. 1999; 15(6): 561-72. doi: 10.2165/00019053-199915060-00004. PMID: 10538329. 
23) Negrini D, Kettle A, Sheppard L, Mills GH, Edbrooke DL. The cost of a hospital ward in Europe: is there a methodology available to accurately measure the costs? J Health Organ Manag. 2004; 18(2-3): 195-206. doi: 10.1108/14777260410548437. PMID: 15366283.

24) Antonella N, Robert O. How Much Do Lab Tests Cost? Analysis of Lacor Hospital Laboratory Services. Journal of Health Policy and development. 2004; 2(2): 144-50.

25) Zamandi M, Zamandi H, Raei B, Norozi A. Activity-based costing in hematology ward of Imam Reza hospital in 2014. Journal of Hospital. 2015; 14(4): 83-93.

26) Hadian M, Mohammadzade A, Imani A, Golestani M. Analysis and Unit Cost Estimation of Services using "Step-Down Method" in Fatemieh Hospital of Semnan University of Medical Sciences-2006 Iran. Journal of Health Administration. 2009; 12(37): 39-48.

27) Torabi A, Keshavarz K, Najafpour Z, Mohamadi E. Computing cost price by using Activity Based Costing (ABC) method in radiology ward of Golestan hospital in Ahvaz University of medical sciences in 2009. Journal of Hospital. 2011; 10(2(37)): 38-49.

28) Saber Mahani A, Barouni M, Bahrami MA, Goodarzi GH, Sheikhgholami S, Ebrahimipour Z, et al. Cost price Estimation of Radiology Services in Shafa Hospital, Kerman, 2010. Journal of Toloo-E-Behdasht. 2011; 10(1(31)): 50-61.

29) Mohammadi Y, Baghestani E, Bahrami MA, Entezarian Ardekani S, Ahmadi Tehrani Gh. Calculating the Cost Price of Dialysis in Shahid Sadoughi Hospital Using Activity Based Costing: Yazd, 2011. Quarterly Journal of Health Accounting. 2012; 1(1): 73-84.

30) Mobasheri M, Sami H, Rafiee A. Calculation of the Final Cost of the Services Offered in Crusher Unit of Ayatollah Kashani Hospital of Shahrekord Using Activity-based Costing Technique. Journal of Health Information Management. 2015; 11(7): 889-95. 